\title{
In-Silico Analysis of the Interaction of Quinalphos and 2- Hydroxyquinoxaline with Organophosphate Hydrolase and Oxygenases
} \author{
Rajasekhar Reddy Bontha ${ }^{1, *(D)}$

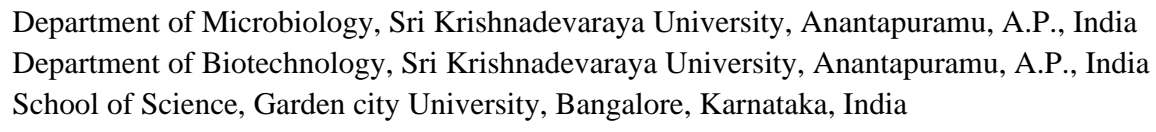

Kanderi Dileep Kumar ${ }^{1} \mathbb{D}$, Satyanarayana Swamy Vyshnava ${ }^{2} \mathbb{D}$, Balappagari Somappagari Shanthi Kumari ', KalvaPraveen Kumar ${ }^{3}$, Kurava Yagna Usha ', Goukanapalle Praveen Kumar Reddy ',

Scopus Author ID 57189365394

Received: 23.02.2021; Revised: 25.03.2021; Accepted: 30.03.2021; Published: 20.04.2021

\begin{abstract}
The present ecological niche is polluted with xenobiotics, which are harder to eliminate from the environment. This current study aims to understand the nature of bacteria which can digest and assimilate these toxic chemicals through computational analysis with bacterial enzyme system; the overall docking predicted the comparative binding efficiency of Quinalphos and 2-Hydroxyquinoxline with Organophosphate hydrolase and Oxygenases (mono-and di-). The dioxygenase shows predominant fitting with $2 \mathrm{HQ}$ based on comparative global energies around $-7.1 \mathrm{kcal} / \mathrm{mol}$ through GLU-267, HIS-214, TYR-257 SER-251 amino acid through hydrogen bonding of active site. The obtained results showed the binding affinity of the selected ligands enhances the metabolism in the physiological state.
\end{abstract}

Keywords: biodegradation; DO; molecular docking; OPH; pesticides; MO.

(C) 2021 by the authors. This article is an open-access article distributed under the terms and conditions of the Creative Commons Attribution (CC BY) license (https://creativecommons.org/licenses/by/4.0/).

\section{Introduction}

Nowadays, greater than thousands of pesticides or agrochemicals have been applied in agriculture at the different growth phases viz start of germination to the fruiting stages of vegetable or fruits or food grain crops. Pesticides applied in agriculture have a different role, such as meeting the requirements of nutrients in soils, stopping the growth of phytopathogens, and managing plant diseases [1]. Around 4.6 metric tons of pesticides are annually released into the environment globally, while only $1 \%$ of the pesticides are effective and $99 \%$ of the pesticides are contaminating the soil, water bodies, and atmospheric ecosystems and finally absorbed by almost every non-target organism [2]. Among the pesticides, the organophosphorus (OPPs) class is the second major group of pesticides widely employed in agricultural practice for more than 40 years. The toxic effect of OPPs is achieved by inhibiting acetylcholinesterase, an enzyme necessary for normal nerve impulse transmission [3].

Most of the OPPs have a similar general structure containing three phospho-ester linkages, and hydrolysis of one of the phospho-ester bonds dramatically reduces the toxicity of the pesticides by eliminating their acetylcholinesterase-inactivating properties [4]. Important organophosphate pesticides are quinalphos, malathion, methyl parathion, diazinon, endosulfan, 
dimethoate, chlorpyrifos, profenofos, and monocrotophos. But the uninterrupted use of these chemical pesticides in agricultural land adversely affected the natural properties, including texture, the productivity of both plant and soil, native soil microflora, and the encompassing environments [5]. After applying pesticides on vegetables, fruits, and crops, a certain percentage of these pesticides get accumulated in different parts of crops and fruits as chemical residues. The ingestion of these pesticide residues shows carcinogenic, mutagenic, genotoxic, and cytotoxic effects and various health-related issues in human beings [1]. The presence of pesticides in ecosystems, especially at higher concentrations due to accidental spills, pesticide container disposals, and discharge of effluents from pesticide manufacturing units, poses concern about natural resources' sustainability - soil, water, and atmosphere to support life processes and health. Different methods evolved during the last two decades - physical, chemical, and biological, to reduce pesticides and agrochemicals in sites in environments with high doses [6]. Among these methods, microbial bioremediation would be a promising approach to the degradation of pesticides and agrochemicals in the soil environment and involves using pesticide-degrading microbes isolated from different locations [7]. Bacterial species isolated from different samples include Bacillus [8], Bacillus thuringiensis [9], Ochrobactrum sp. [10], Pseudomonas [11], Pseudomonas spp. [8], Pseudomonas sp., Pseudomonas aeruginosa Q10, Serratia sp. [12] involved in the degradation of Quinaphos while bacterial isolates Ochrobactrum sp. HQ1 [13] and Bacillus sp. [14] carried out the degradation of 2-hydroxyquinoxaline (2HQ). Microbial degradation of the organophosphate class of pesticides proceeds either by active metabolism or co-metabolism [15]. Metabolism of organophosphate pesticides is initiated mainly with hydrolysis by the action of Organophosphate hydrolase $(\mathrm{OPH})$ and then followed by mono and dioxygenases in bacteria to mammals [16, 17]. Parathion hydrolases (OPH) isolated from Flavobacterium sp., Organophosphorous acid anhydrolase in Alteromonas sp., exhibited homology with Phosphotriesterase protein in Escherichia coli [18, 19]. The bacterial enzyme Organophosphorus hydrolase $(\mathrm{OPH})$ has also been shown to degrade a wide range of different organophosphorus pesticides [20-30]. A gene (OPD) encoding the enzyme-OPH in the degradation of organophosphates is present in different bacteria with degradation traits isolated from geographically different regions. Based on the recent literature, oxygenases are the enzymes that catalyze the insertion of one or two oxygen atoms into metabolites formed from OPPs. There are two classes of oxygenases that have been identified based on the mode of reaction with the substrate, viz monooxygenases, and dioxygenases. Monooxygenases incorporate oxygen molecules into the substrate, whereas dioxygenases add both oxygen atoms of an oxygen molecule [31]. Mono and dioxygenase enzymes add molecular dioxygen into the aromatic ring by using co-factor NADH, NADPH during degradation. These enzymes play a significant role in the bacterial catabolism of xenobiotic compounds, incorporating one and two hydroxyl groups into the aromatic ring to increase the reactivity of these compounds, making them susceptible to enzymatic ring fission reactions [32].

Pesticide pollution has become a global problem. Degradation capacity of microbial cultures will be put to application in bioremediation to mitigate pesticide pollution in a better way if the mechanism of interaction of OPPs and their metabolites with enzyme proteins in microbial cultures is understood to a greater extent. To find an economical, effective and safe way to degrade residues of pesticides in the environment, many researchers tested the microbes for their bioremediation [11-13]. In the present study, we described the practicable binding mechanism of pesticides - Quinalphos and 2-Hydroxyqunaoinline with microbial enzymes 
such as Organophosphate hydrolase, Oxygenases (mono-and di-) using the In-silico approaches.

\section{Materials and Methods}

For this study, the protein models - Phosphotriesterase (Organophosphate hydrolase), Dioxygenase, and Monoxygenase were retrieved from rcsb.org. The PDB IDs for the selected proteins are 1BF6 (Phosphotriesterase homology protein from Escherichia coli for Phosphotriesterase), 1F1R (Crystal structure of homoprotocatechuate 2,3-dioxygenase from Arthrobacter globiformis (native, non-cryo) for Dioxygenase) and 6G71 (Structure of CYP1232A24 from Arthrobacter sp. for Monoxygenase). Quinalphos and 2hydroxyquinoxline were selected as ligands and drawn for $3 \mathrm{D}$ models using ChemDraw ${ }^{\mathrm{TM}}$ (PerkinElmer) [33].

Raw data of each PDB IDs were read, and protein preparation was done for energy normalization to remove the bind ligands and water molecules using Discovery studio client [34]. These normalized proteins and ligands. PDB files are listed in the Auto dock standalone docking software [35,36], all the values kept in default as coordinates designated through Discovery studio client and Auto dock tools (Clustering RMSD value of 4.0). Later the PDB files for normalized proteins and ligands are submitted to the server through rigid docking. After docking in the Auto dock, results appeared in the top 10 ranks based on the lowest energy available for the ligand binding. Each PDB file was selected and analyzed using PyMolTM software (Schrödinger) [37] and Discovery studio client. In PyMol ${ }^{\mathrm{TM}}$ software, amino acid residues were selected according to the binding efficiency towards the ligands.

\section{Results and Discussion}

The hydrolysis activity function of organophosphatase hydrolase (OPH) [36] and oxygen atom incorporating activity function of oxygenases [31] are well-established. Structures generated after docking through Auto dock software, the .pdb files were refined and selected based on the relative ranking (Docking score through least global energies) concerning the lowest binding energy (Global energy, i.e., $\Delta \mathrm{G}$ ) for the ligand. In Figure 1a, OPH docking results reveal the binding affinity of 2-hydroxyquinoxaline (2HQ) with TYR-84 (TYR-84 HIS186 and ASP-243 involved in nonbonding interactions) while the same enzyme binds Quinalphos (QP) as shown in the Figure 1b through LYS-213 higher affinity thought hydrogen bonding (TYR-216, LYS-213, ARG-246, ASP-243 and HIS-249 involved in nonbonding interactions). Our results were supported by the observations reported in Efremenko, and Sergeeva 2001 [38 were mentions that OPH used amino acid residues - HIS, TYR, SER, PHE, and LEU, in particular, LYS along with imide group with co-factor $\mathrm{Zn}$ ions for binding of substrate analogs.

In addition to $\mathrm{OPH}$, experiments were also carried out to dock 2HQ and QP with other enzymes which are important in degradation, such as Oxygenases - Monooxygenase (MO) and Dioxygenase (DO). The monooxygenase (6G71 PBD ID) results in Figure 2a interact with ligand 2HQ with active site amino acids ASP-243 and ARG-242 are in hydrogen bonding (ASP-243, ARG-242, PHE-386, and GLY-382 involved in nonbonding interactions). Whereas in Figure 2b, binding of QP to Monoxygenase involved amino acid residues - GLN-164 and ARG-242 through hydrogen bonding (PHE-386, GLN-164, ARG-242, and MET-133 involved in nonbonding interactions). 
(a)

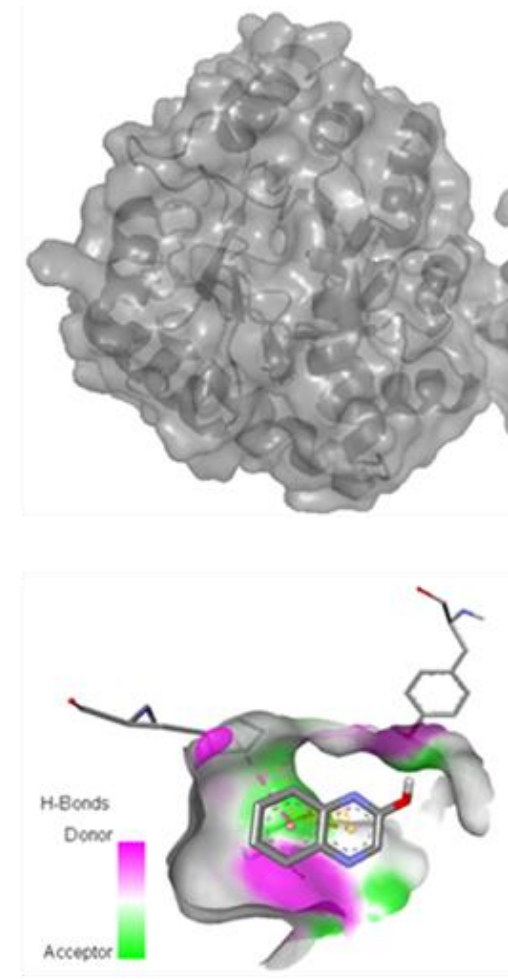

(b)
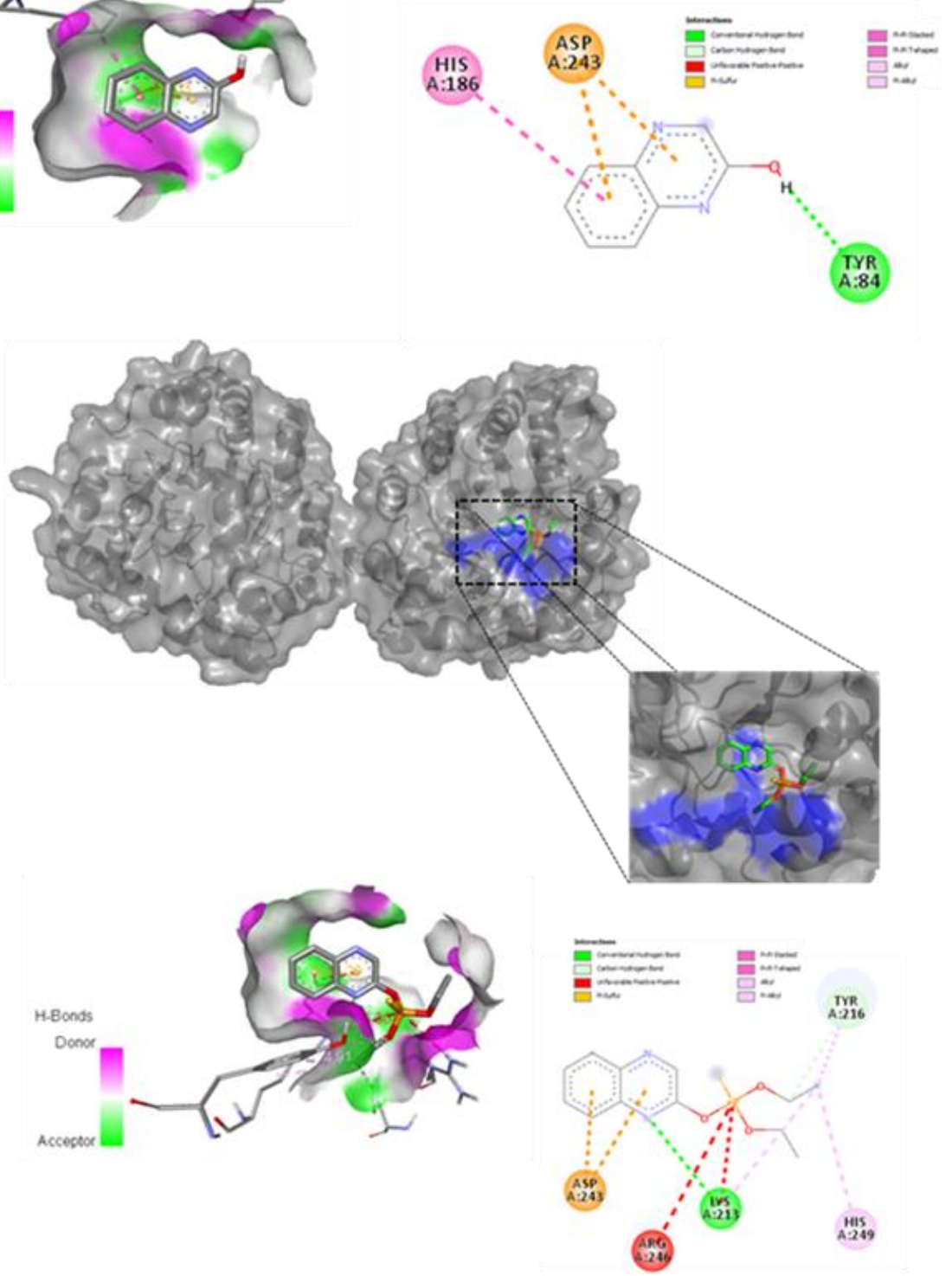

Figure 1. Phosphotriesterase (PDB ID 1BF6) with 2-hydroxyquinoxline and Quinalphos (a) surface and structure shows that proximal fitting was zoomed for amino acids with 2-hydroxyquinoxline and mentioned the perspective with 3D and 2D viewing for bonding structures (b) surface and structure shows that proximal fitting was zoomed for amino acids with Quinalphos and mentioned the perspective with 3D and 2D viewing for bonding structures. 
(a)

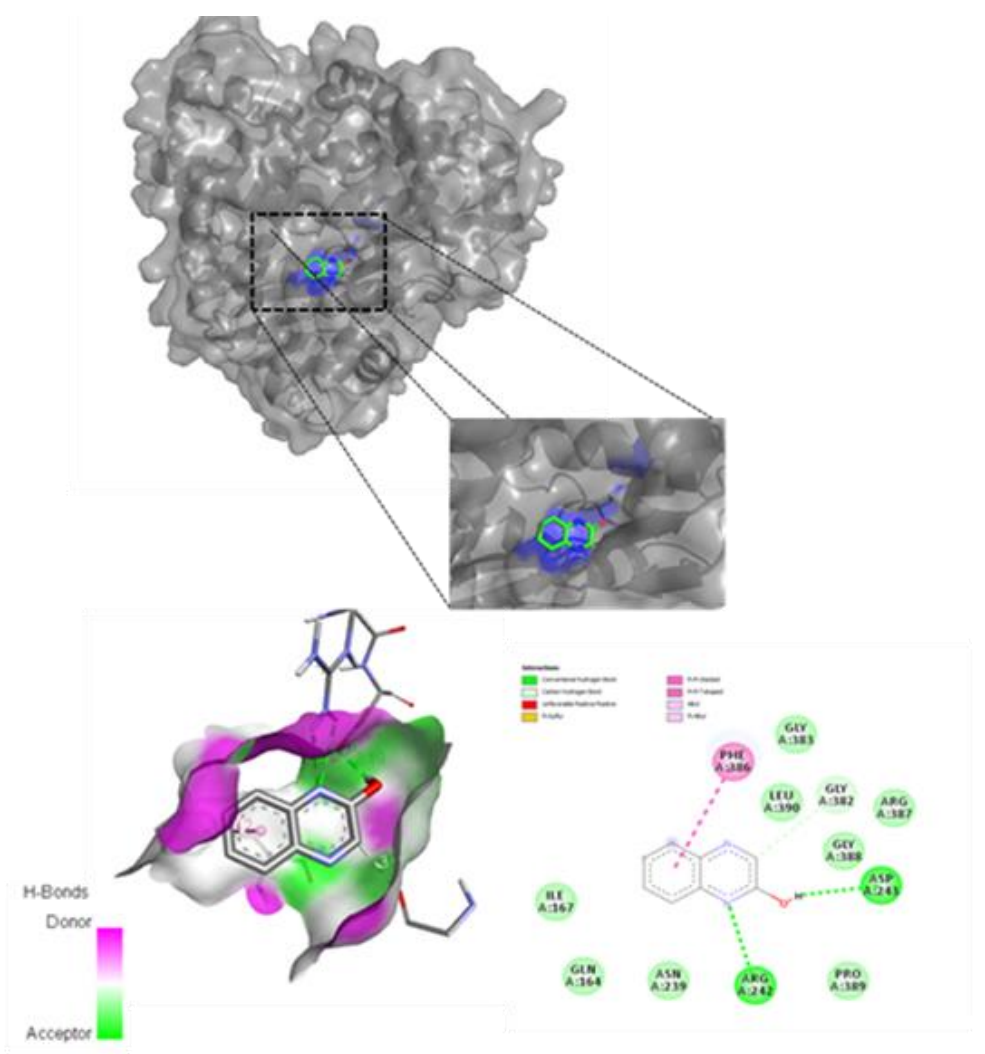

(b)

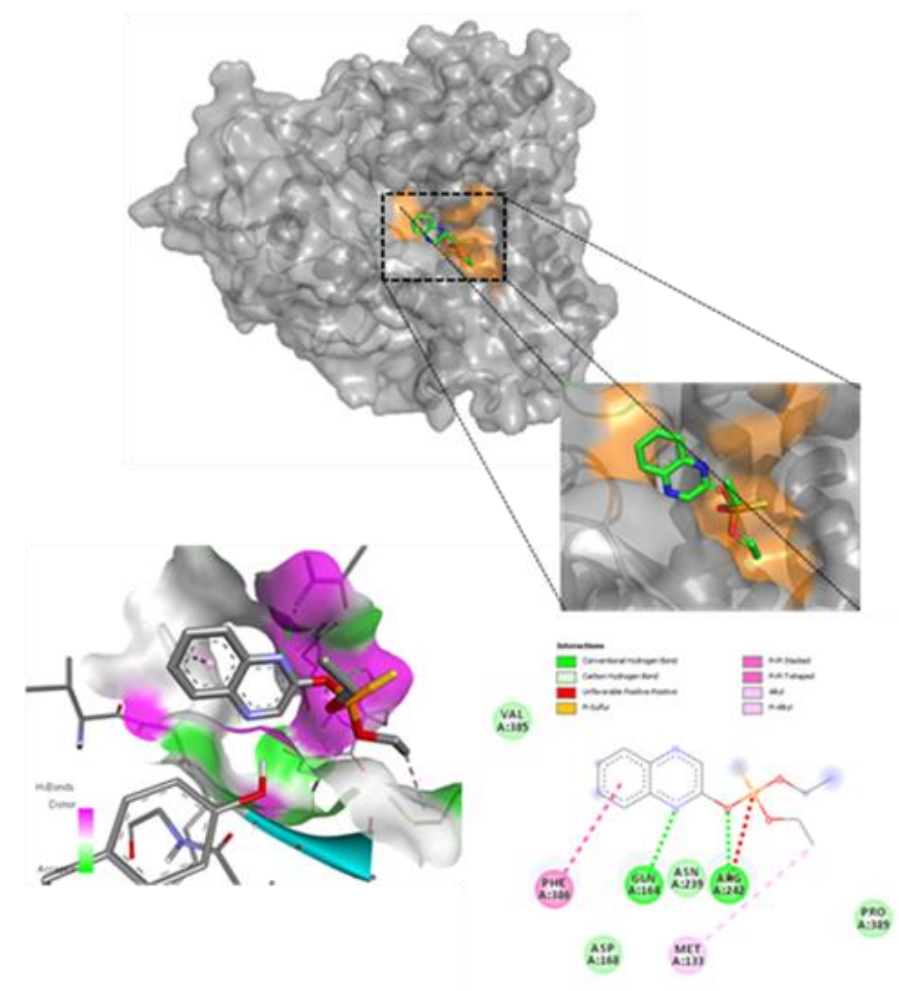

Figure 2. Monoxygenase (PDB ID 6G71) with 2-hydroxyquinoxline and Quinalphos (a) surface and structure shows that proximal fitting was zoomed for amino acids with 2-hydroxyquinoxline and mentioned the perspective with 3D and 2D viewing for bonding structures (b) surface and structure shows that proximal fitting was zoomed for amino acids with Quinalphos and mentioned the perspective with 3D and 2D viewing for bonding structures. 
(a)

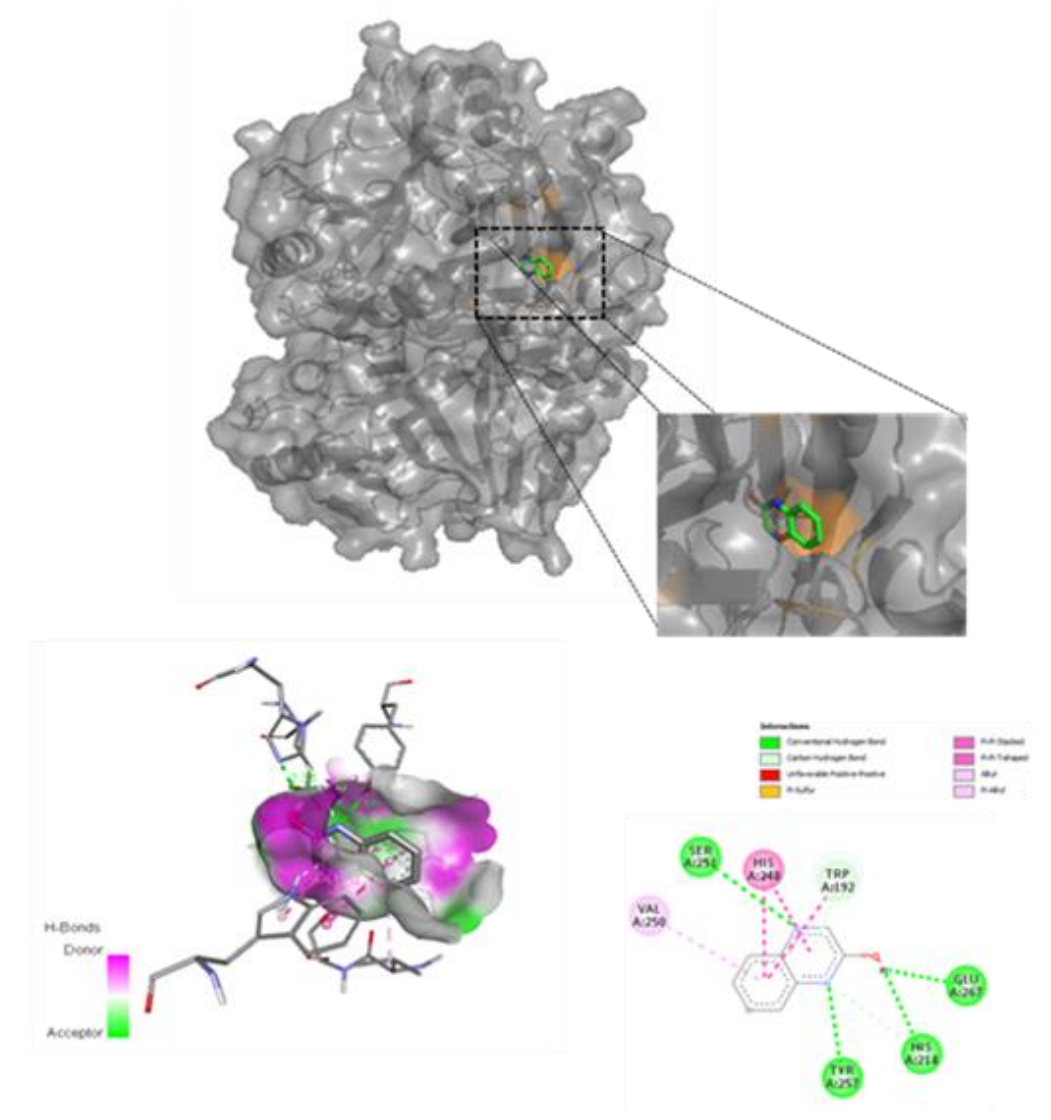

(b)
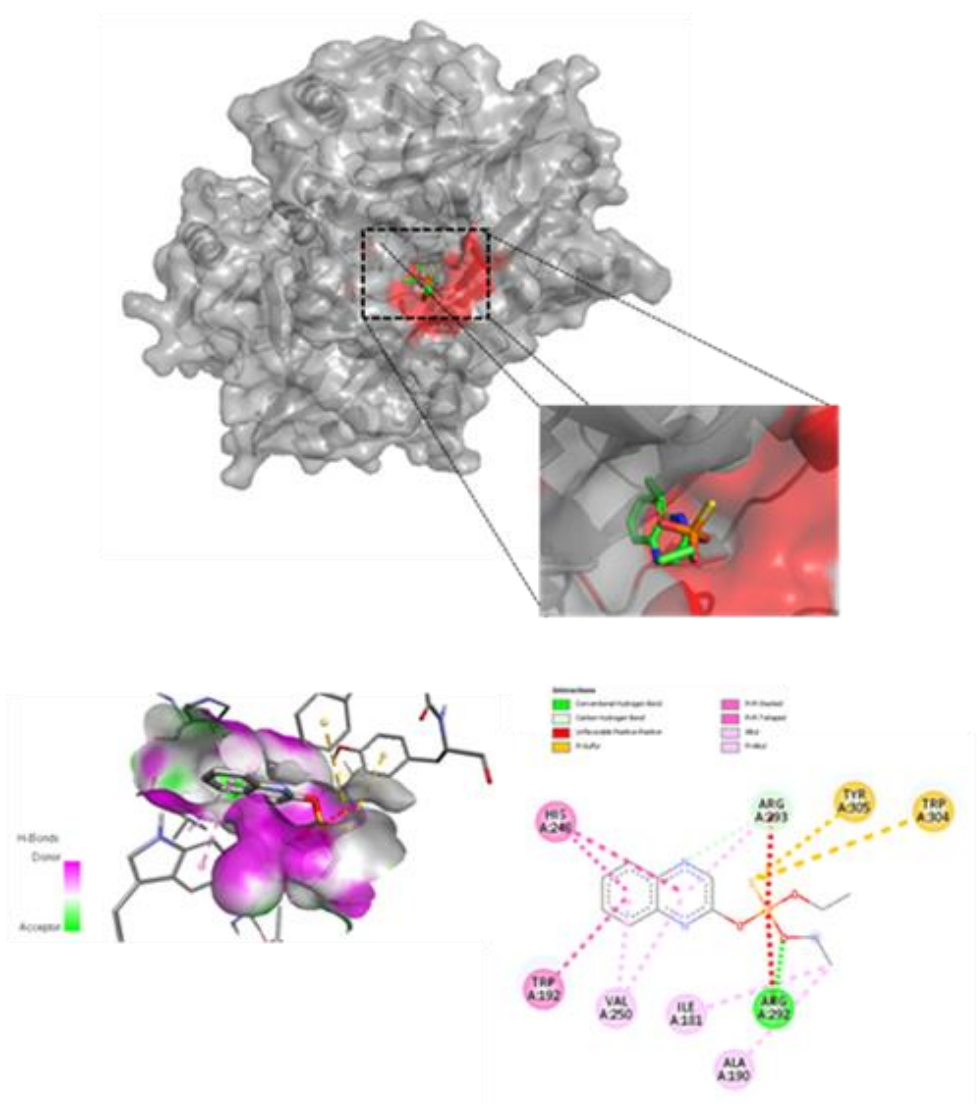

Figure 3. Dioxygenase (PDB ID 1F1R) with 2-hydroxyquinoxline and Quinalphos (a) surface and structure shows that proximal fitting was zoomed for amino acids with 2-hydroxyquinoxline and mentioned the perspective with $3 \mathrm{D}$ and 2D viewing for bonding structures (b) surface and structure shows that proximal fitting was zoomed for amino acids with Quinalphos and mentioned the perspective with 3D and 2D viewing for bonding structures. 
Table 1. Molecular docking results for interacting amino acids in individual receptors for respective ligands representing the score with global affinity models as standardized in Auto dock.

\begin{tabular}{|c|c|c|c|c|c|}
\hline Enzyme & PDB ID & Ligands & $\begin{array}{l}\text { Binding Affinity } \\
\text { (Kcal/mol) }\end{array}$ & $\begin{array}{l}\text { Interacted } \\
\text { amino acids }\end{array}$ & $\begin{array}{l}\text { Interacted amino acids } \\
\text { with hydrogens bonds }\end{array}$ \\
\hline \multirow[t]{2}{*}{$\begin{array}{l}\text { Organophosphatase } \\
\text { hydrolase }\end{array}$} & \multirow[b]{2}{*}{ 1BF6 } & $2 \mathrm{HQ}$ & -5.2 & $\begin{array}{l}\text { HIS-186 } \\
\text { ASP-243 } \\
\text { TYR-84 }\end{array}$ & TYR-84 \\
\hline & & QP & -6.4 & $\begin{array}{l}\text { TYR-216 } \\
\text { LYS-213 } \\
\text { ARG-246 } \\
\text { ASP-243 } \\
\text { HIS-249 }\end{array}$ & LYS-213 \\
\hline \multirow[t]{2}{*}{ Monooxygenase } & \multirow{2}{*}{$6 \mathrm{G} 71$} & $2 \mathrm{HQ}$ & -5.6 & $\begin{array}{l}\text { ASP-243 } \\
\text { ARG-242 } \\
\text { PHE-386 } \\
\text { GLY-382 }\end{array}$ & $\begin{array}{l}\text { ASP-243 } \\
\text { ARG-242 }\end{array}$ \\
\hline & & $\mathrm{QP}$ & -5.7 & $\begin{array}{l}\text { PHE-386 } \\
\text { GLN-164 } \\
\text { ARG-242 } \\
\text { MET-133 }\end{array}$ & $\begin{array}{l}\text { GLN-164 } \\
\text { ARG-242 }\end{array}$ \\
\hline \multirow[t]{2}{*}{ Dioxygenase } & \multirow[b]{2}{*}{$1 \mathrm{~F} 1 \mathrm{R}$} & $2 H Q$ & -7.1 & $\begin{array}{l}\text { SER-251 } \\
\text { HIS-248 } \\
\text { VAL-250 } \\
\text { TRP-192 } \\
\text { GLU-267 } \\
\text { HIS-214 } \\
\text { TYR-257 }\end{array}$ & $\begin{array}{l}\text { GLU-267 } \\
\text { HIS-214 } \\
\text { TYR-257 } \\
\text { SER-251 }\end{array}$ \\
\hline & & QP & -6.1 & $\begin{array}{l}\text { HIS-248 } \\
\text { TRP-192 } \\
\text { VAL-250 } \\
\text { ILE-181 } \\
\text { ALA-190 } \\
\text { ARG-292 } \\
\text { ARG-293 } \\
\text { TYR-305 } \\
\text { TRP-304 }\end{array}$ & ARG-292 \\
\hline
\end{tabular}

In continuation, the docking results for Dioxygenase indicate higher efficiency as shown in Figure $3 \mathrm{a}$ in binding $2 \mathrm{HQ}$ through the participation of the amino acid residues GLU267, HIS-214, SER-251, and TYR-257 with hydrogen bond (SER-251, HIS-248, VAL-250, TRP-192, GLU-267, HIS-214 and TYR-257 involved in nonbonding interactions) while binding of QP to DO romped the amino acid residues ARG-292 with hydrogen bond (HIS-248, TRP-192, VAL-250, ILE-181, ALA-190, ARG-292, ARG-293, TYR-305 and TRP-304 involved in nonbonding interactions) shown in Figure $3 \mathrm{~b}$. The consolidated energies for affinity and the interacted amino acids are tabulated under Table 1.

In the overall procedure, the fitting model for ligands - 2HQ and QP with the selected enzymes are presented in Table 1. DO exhibits more binding efficiency towards ligands for 2HQ about $-7.1 \mathrm{kcal} / \mathrm{mol}$, while $\mathrm{OPH}$ shows a higher affinity towards QP about $-6.4 \mathrm{kcal} / \mathrm{mol}$. Our results were in agreement with the results of $p$-nitrophenol interaction with Monoxygenase $[39,40]$. According to this study, PNP- monooxygenase docked $p$-nitrophenol in the presence or absence of coenzymes, FAD, and NADH and provided a good correlation with the established experimental evidence. Oxygenases, in particular MO, in the present study exhibited similar results of weaker binding efficacies with the QP and 2 HQ ligands in the absence of coenzymes, and this was comparable to the binding efficiency of 2-amino-5chlorophenol with 2-Amino-5-chlorophenol 1, 6-dioxygenase from Comamonas sp, [41-42] relevant to our fitting docking model for DO.

Based on the docking refinement studies of OPH, MO, and DO enzymes fitting models, QP and 2HQ were bonded to assigned enzyme active pockets, and amino acid residues in 
enzyme proteins may facilitate degradation in native bacteria secretary environment. The evidence of mechanism can be studied through prospectus wet lab analysis, where these findings may reflect the bacterial enzymatic environment in-vivo conditions.

\section{Conclusions}

The computational docking study indicated the method of predicted degradation processes for the QP and 2HQ under the OPH, MO, and DO enzymes' influence. The proximal fitting of the QP and 2HQ in the above enzymes shows the mere activity, where the amino acid residues at active sites are compactly bonding with less than $4 \AA$, representing the reaction vicinity for the enzymes. Thus, the present research will be useful for assigning the possible interaction mechanism for degradation of the pesticides and Agri products toxic to the environment and its biome.

\section{Funding}

Mr. K. Dileep Kumar duly acknowledges that University Grant Commission (UGC Lr.F.7262/2009 BSR) New Delhi, the financial assistance in the form of fellowship grant.

\section{Acknowledgments}

The authors are grateful for the free access to online resources that allowed them to complete this article.

\section{Conflicts of Interest}

The authors declare no conflict of interest.

\section{References}

1. Singh, D.; Singh, S.K.; Modi, A.; Singh, P.K.; Zhimo, V.Y.; Kumar A. Impacts of agrochemicals on soil microbiology and food quality. In: Agrochemicals Detection, Treatment and Remediation. Elsevier, 2020; pp. 101-116.

2. Durán-Lara, E.F.; Valderrama, A.; Marican, A. Natural Organic Compounds for Application in Organic Farming. Agriculture 2020, 10, https://doi.org/10.3390/agriculture10020041.

3. Souza, F.R.d.; Rodrigues Garcia, D.; Cuya, T.; Pimentel, A.S.; Gonçalves, A.d.S.; Alencastro, R.B.d.; França, T.C.C. Molecular Modeling Study of Uncharged Oximes Compared to HI-6 and 2-PAM Inside Human AChE Sarin and VX Conjugates. ACS Omega 2020, 5, 4490-4500, https://doi.org/10.1021/acsomega.9b03737.

4. Mulla, S.I.; Ameen, F.; Talwar, M.P.; Eqani, S.A.M.A.S.; Bharagava, R.N.; Saxena, G.; Tallur, P.N.; Ninnekar, H.Z. Organophosphate pesticides: impact on environment, toxicity, and their degradation. In: Bioremediation of Industrial Waste for Environmental Safety. Springer, Singapore. 2020; pp. 265-290, https://doi.org/10.1007/978-981-13-1891-7_13.

5. Singh, B. Are Nitrogen Fertilizers Deleterious to Soil Health? Agronomy 2018, 8, https://doi.org/10.3390/agronomy8040048.

6. Baldissarelli, D.P.; Vargas, G.D.L.P.; Korf, E.P.; Galon, L.; Kaufmann, C.; Santos, J.B. Remediation of Soils Contaminated by Pesticides Using Physicochemical Processes: a Brief Review. Planta Daninha 2019, 37, https://doi.org/10.1590/s0100-83582019370100054.

7. Kumar, M.; Yadav, A.N.; Saxena, R.; Paul, D.; Tomar, R.S. Biodiversity of pesticides degrading microbial communities and their environmental impact. Biocatalysis and Agricultural Biotechnology 2021, 31, https://doi.org/10.1016/j.bcab.2020.101883.

8. $\quad$ Lin, Z.; Zhang, W.; Pang, S.; Huang, Y.; Mishra, S.; Bhatt, P.; Chen, S. Current Approaches to and Future Perspectives on Methomyl Degradation in Contaminated Soil/Water Environments. Molecules 2020, 25, https://doi.org/10.3390/molecules25030738.

9. Bhatt, P.; Huang, Y.; Zhang, W.; Sharma, A.; Chen, S. Enhanced Cypermethrin Degradation Kinetics and Metabolic Pathway in Bacillus thuringiensis Strain SG4. Microorganisms 2020, 8, https://doi.org/10.3390/microorganisms8020223. 
10. Talwar, M.P.; Mulla, S.I.; Ninnekar, H.Z. Biodegradation of organophosphate pesticide quinalphos by Ochrobactrum sp. strain HZM. Journal of Applied Microbiology 2014, 117, 1283-1292, https://doi.org/10.1111/jam.12627.

11. Pawar, K.; Mali, G. Biodegradation of Quinolphos insecticide by Pseudomonas strain isolated from Grape rhizosphere soils. Int. J. Curr. Microbiol. App. Sci. 2014, 3, 606-613.

12. Nair, A.M.; Rebello, S.; Rishad, K.S.; Asok, A.K.; Jisha, M.S. Biosurfactant Facilitated Biodegradation of Quinalphos at High Concentrations by Pseudomonas aeruginosa Q10. Soil and Sediment Contamination: An International Journal 2015, 24, 542-553, https://doi.org/10.1080/15320383.2015.988205.

13. Subba Reddy, G.V.; Rafi, M.M.; Rubesh Kumar, S.; Khayalethu, N.; Muralidhara Rao, D.; Manjunatha, B.; Philip, G.H.; Reddy, B.R. Optimization study of 2-hydroxyquinoxaline (2-HQ) biodegradation by Ochrobactrum sp. HQ1. 3 Biotech 2016, 6, https://doi.org/10.1007/s13205-015-0358-6.

14. Reddy, G.V.S.; Reddy, B.R.; Tlou, M.G. Biodegradation of 2-hydroxyquinoxaline (2-HQ) by Bacillus sp. Journal of Hazardous Materials 2014, 278, 100-107, https://doi.org/10.1016/j.jhazmat.2014.05.080.

15. Dhakal, R.; Singh, D.N. Biopesticides: a key to sustainable agriculture. Int J Pure App Biosci, 2019, 7(3), 391-396. http://dx.doi.org/10.18782/2320-7051.7034

16. Kan, J.; Peng, T.; Huang, T.; Xiong, G.; Hu, Z. NarL, a Novel Repressor for CYP108j1 Expression during PAHs Degradation in Rhodococcus sp. P14. Int J Mol Sci 2020, 21, https://doi.org/10.3390/ijms21030983.

17. Bhandari, S.; Poudel, D.K.; Marahatha, R.; Dawadi, S.; Khadayat, K.; Phuyal, S.; Shrestha, S.; Gaire, S.; Basnet, K.; Khadka, U.; Parajuli, N. Microbial Enzymes Used in Bioremediation. Journal of Chemistry 2021, 2021, https://doi.org/10.1155/2021/8849512.

18. Eddleston, M.; Karalliedde, L.; Buckley, N.; Fernando, R.; Hutchinson, G.; Isbister, G.; Konradsen, F.; Murray, D.; Piola, J.C.; Senanayake, N. Pesticide poisoning in the developing world - a minimum pesticides list. The Lancet 2002, 360, 1163-1167, https://doi.org/10.1016/S0140-6736(02)11204-9.

19. Sogorb, M.A.; Vilanova, E.; Carrera, V. Future applications of phosphotriesterases in the prophylaxis and treatment of organophosporus insecticide and nerve agent poisonings. Toxicology Letters 2004, 151, 219233, https://doi.org/10.1016/j.toxlet.2004.01.022.

20. Benning, M.M.; Hong, S.-B.; Raushel, F.M.; Holden, H.M. The Binding of Substrate Analogs to Phosphotriesterase *. Journal of Biological Chemistry 2000, 275, 30556-30560, https://doi.org/10.1074/jbc.M003852200.

21. Li, Z.; Jiang, Y.; Guengerich, F.P.; Ma, L.; Li, S.; Zhang, W. Engineering cytochrome P450 enzyme systems for biomedical and biotechnological applications. Journal of Biological Chemistry 2020, 295, 833-849, https://doi.org/10.1016/S0021-9258(17)49939-X.

22. Cho, C.M.-H.; Mulchandani, A.; Chen, W. Bacterial Cell Surface Display of Organophosphorus Hydrolase for Selective Screening of Improved Hydrolysis of Organophosphate Nerve Agents. Applied and Environmental Microbiology 2002, 68, 2026-2030, https://doi.org/10.1128/AEM.68.4.2026-2030.2002.

23. Efremenko, E.; Peregudov, A.; Kildeeva, N.; Perminov, P.; Varfolomeyev, S. New enzymatic immobilized biocatalysts for detoxification of organophosphorus compounds. Biocatalysis and Biotransformation 2005 , 23, 103-108, https://doi.org/10.1080/10242420500132474.

24. Arora, N.K.; Mishra, J.; Mishra, V. Microbial enzymes: roles and applications in industries. Springer Singapore. 2020; pp. 1-110.

25. Ortiz-Hernández, M.L.; Quintero-Ramírez, R.; Nava-Ocampo, A.A.; Bello-Ramírez, A.M. Study of the mechanism of Flavobacterium sp. for hydrolyzing organophosphate pesticides. Fundamental \& Clinical Pharmacology 2003, 17, 717-723, https://doi.org/10.1046/j.1472-8206.2003.00202.x.

26. Haque, A.M.; Hwang, C.E.; Kim, S.C.; Cho, D.Y.; Lee, H.Y.; Cho, K.M.; Lee, J.H. Biodegradation of organophosphorus insecticides by two organophosphorus hydrolase genes (opdA and opdE) from isolated Leuconostoc mesenteroides WCP307 of kimchi origin. Process Biochemistry 2020, 94, 340-348, https://doi.org/10.1016/j.procbio.2020.04.026.

27. Jia, Y.; Eltoukhy, A.; Wang, J.; Li, X.; Hlaing, T.S.; Aung, M.M.; Nwe, M.T.; Lamraoui, I.; Yan, Y. Biodegradation of Bisphenol A by Sphingobium sp. YC-JY1 and the Essential Role of Cytochrome P450 Monooxygenase. International journal of molecular sciences 2020, 21, https://doi.org/10.3390/ijms21103588.

28. Raushel, F.M. Bacterial detoxification of organophosphate nerve agents. Current Opinion in Microbiology 2002, 5, 288-295, https://doi.org/10.1016/S1369-5274(02)00314-4.

29. Raushel, F.M.; Holden, H.M. Phosphotriesterase: an enzyme in search of its natural substrate. Adv Enzymol. Relat. Areas Mol. Biol. 2000, 74, 51-93, https://doi.org/10.1002/9780470123201.ch2.

30. Singh, B.K.; Walker, A. Microbial degradation of organophosphorus compounds. FEMS Microbiology Reviews 2006, 30, 428-471, https://doi.org/10.1111/j.1574-6976.2006.00018.x.

31. Sogorb, M.A.; Vilanova, E. Enzymes involved in the detoxification of organophosphorus, carbamate and pyrethroid insecticides through hydrolysis. Toxicology Letters 2002, 128, 215-228, https://doi.org/10.1016/S0378-4274(01)00543-4.

32. Arora, P.K.; Kumar, M.; Chauhan, A.; Raghava, G.P.S.; Jain, R.K. OxDBase: a database of oxygenases involved in biodegradation. BMC Research Notes 2009, 2, https://doi.org/10.1186/1756-0500-2-67. 
33. Mishra, V.; Lal, R.; Srinivasan. Enzymes and Operons Mediating Xenobiotic Degradation in Bacteria. Critical Reviews in Microbiology 2001, 27, 133-166, https://doi.org/10.1080/20014091096729.

34. Cousins, K.R. Computer Review of ChemDraw Ultra 12.0. Journal of the American Chemical Society 2011, 133, 8388-8388, https://doi.org/10.1021/ja204075s.

35. Biovia D.S. Discovery studio modeling environment. Release, 2017.

36. Morris, G.M.; Huey, R.; Lindstrom, W.; Sanner, M.F.; Belew, R.K.; Goodsell, D.S.; Olson, A.J. AutoDock4 and AutoDockTools4: Automated docking with selective receptor flexibility. Journal of Computational Chemistry 2009, 30, 2785-2791, https://doi.org/10.1002/jcc.21256.

37. Trott, O.; Olson, A.J. AutoDock Vina: Improving the speed and accuracy of docking with a new scoring function, efficient optimization, and multithreading. Journal of Computational Chemistry 2010, 31, 455461, https://doi.org/10.1002/jcc.21334.

38. DeLano W.L. PyMOL, 2002.

39. Rangasamy, K.,; Athiappan, M.; Devarajan, N.; Parray, J.A.; Shameem, N.; Aruljothi, K.; Hashem, A.; Alqarawi, A.A.; Abd_Allah, E.F. Cloning and Expression of the Organophosphate Pesticide-Degrading $\alpha-\beta$ Hydrolase Gene in Plasmid pMK-07 to Confer Cross-Resistance to Antibiotics. BioMed Research International 2018, 2018, https://doi.org/10.1155/2018/1535209.

40. Efremenko, E.N.; Sergeeva, V.S. Organophosphate hydrolase — an enzyme catalyzing degradation of phosphorus-containing toxins and pesticides. Russian Chemical Bulletin 2001, 50, 1826-1832, https://doi.org/10.1023/A:1014377912147.

41. Kallubai, M.; Amineni, U.; Mallavarapu, M.; Kadiyala, V. In Silico Approach to Support that p-Nitrophenol Monooxygenase from Arthrobacter sp. Strain JS443 Catalyzes the Initial Two Sequential Monooxygenations. Interdisciplinary Sciences: Computational Life Sciences 2015, 7, 157-167, https://doi.org/10.1007/s12539-015-0018-x.

42. Monika, K.; Rao, D.M.; Anuraj, N.; Yadav, M,; Rao, N.N.; Venkateswarlu, K. Ligand-Binding Site Analysis of 2-Amino-5-chlorophenol 1, 6-dioxygenase from Comamonas sp. CNB-1 by Molecular Modelling and Docking. Online Journal of Bioinform. 2010, 11, 302-316. 